\title{
Genome instability-related long non-coding RNA in clear renal cell carcinoma determined using computational biology
}

\author{
Yutao Wang ${ }^{1+}$, Kexin Yan ${ }^{2 \dagger}$, Linhui Wang ${ }^{1}$ and Jianbin $\mathrm{Bi}^{{ }^{*}}$
}

\begin{abstract}
Background: There is evidence that long non-coding RNA (IncRNA) is related to genetic stability. However, the complex biological functions of these IncRNAs are unclear.

Method: TCGA - KIRC IncRNAs expression matrix and somatic mutation information data were obtained from TCGA database. "GSVA" package was applied to evaluate the genomic related pathway in each samples. GO and KEGG analysis were performed to show the biological function of IncRNAs-mRNAs. "Survival" package was applied to determine the prognostic significance of IncRNAs. Multivariate Cox proportional hazard regression analysis was applied to conduct IncRNA prognosis model.
\end{abstract}

Results: In the present study, we applied computational biology to identify genome-related long noncoding RNA and identified 26 novel genomic instability-associated IncRNAs in clear cell renal cell carcinoma. We identified a genome instability-derived six IncRNA-based gene signature that significantly divided clear renal cell samples into high- and low-risk groups. We validated it in test cohorts. To further elucidate the role of the six IncRNAs in the model's genome stability, we performed a gene set variation analysis (GSVA) on the matrix. We performed Pearson correlation analysis between the GSVA scores of genomic stability-related pathways and IncRNA. It was determined that LINC00460 and LINC01234 could be used as critical factors in this study. They may influence the genome stability of clear cell carcinoma by participating in mediating critical targets in the base excision repair pathway, the DNA replication pathway, homologous recombination, mismatch repair pathway, and the P53 signaling pathway.

Conclusion subsections: These data suggest that LINC00460 and LINC01234 are crucial for the stability of the clear cell renal cell carcinoma genome.

Keywords: Genome instability, Long non-coding RNA, Computational biology, Gene set variation analysis, Risk signature

\footnotetext{
* Correspondence: jianbinbi@cmu.edu.cn

${ }^{\dagger}$ Yutao Wang and Kexin Yan contributed equally to this work.

'Department of Urology, China Medical University, The First Hospital of China Medical University, Shenyang, Liaoning, China

Full list of author information is available at the end of the article
}

(c) The Author(s). 2021 Open Access This article is licensed under a Creative Commons Attribution 4.0 International License, which permits use, sharing, adaptation, distribution and reproduction in any medium or format, as long as you give appropriate credit to the original author(s) and the source, provide a link to the Creative Commons licence, and indicate if changes were made. The images or other third party material in this article are included in the article's Creative Commons licence, unless indicated otherwise in a credit line to the material. If material is not included in the article's Creative Commons licence and your intended use is not permitted by statutory regulation or exceeds the permitted use, you will need to obtain permission directly from the copyright holder. To view a copy of this licence, visit http://creativecommons.org/licenses/by/4.0/ The Creative Commons Public Domain Dedication waiver (http://creativecommons.org/publicdomain/zero/1.0/) applies to the data made available in this article, unless otherwise stated in a credit line to the data. 


\section{Introduction}

Clear cell renal cell carcinoma (ccRCC) is the most common subtype of renal cell carcinoma, and ccRCC accounts for 80 to $90 \%$ of all renal cell carcinomas. ccRCC is a potentially invasive tumor with an overall progression-free survival rate of $70 \%$ and a cancerspecific mortality rate of $24 \%$ [1]. It is $1.5-2.0$ times more common in men than in women. Advanced RCC has a five-year survival rate of $11.7 \%$ [2]. Risk factors include smoking, obesity, high blood pressure, chronic kidney disease, and exposure to certain chemicals and heavy metals [3]. The diagnosis of ccRCC has been increasing over the past few years. Although surgery is the most common treatment option, early diagnosis is difficult, and many patients have metastatic disease by this time [4]. For patients with advanced ccRCC or relapse, many molecular-targeted drugs have been used as firstline therapies. Nevertheless, outcomes are poor due to the side effects of these agents and individual differences in individual drug sensitivities [5].

It is a fundamental challenge for cells to copy their genetic material for daughter cells accurately. Once this process goes wrong, genomic instability occurs [6]. The level of genomic instability is reflected in nucleotide instability, microsatellite instability, and chromosome instability [7]. DNA damage can be caused by mistakes in DNA replication caused by genotoxic compounds or ultraviolet and ionizing radiation. Incorrect DNA replication can lead to mutations or blocked replication, leading to chromosome breakage, rearrangement, and dislocation [8]. Genomic instability is an essential source of genetic diversity within tumors. Oncogene expression drives proliferation by interfering with regulatory pathways that control cell cycle progression. Genomic instability produces large-scale genetic aberrations but also increases point mutations in protein-coding genes. The estimated mutation rate in tumors is an order of magnitude higher than that of typical healthy tissue. Genomic instability also changes as tumors develop, and this trait could become a target for treatment [9].

Recent advances in sequencing technology have revealed that only $2 \%$ of the human genome codes for proteins [10]. Non-coding RNAs are classified into small non-coding RNAs and long non-coding RNAs according to their size. Long non-coding RNA (lncRNA) predominate. LncRNAs play central roles in many cellular mechanisms, including regulation of cell processes [11]. They also regulate pathophysiological processes through gene imprinting, histone modification, chromatin remodeling, and other mechanisms $[12,13]$. LncRNAs also play essential roles in cancer. They are involved in chromatin remodeling and transcriptional and posttranscriptional regulation through various chromatinbased mechanisms and interactions with other RNA species $[14,15]$. LncRNA imbalances can alter functions such as cell proliferation, anti-apoptosis, angiogenesis, metastasis, and tumor suppression [16]. Depending on their positions and distribution in the genome, lncRNAs directly or indirectly affect the transcription of various proteins through transcriptional and post-transcriptional changes, some of which may mediate tumor inhibition or promotion [17].

Because chemotherapy, radiation therapy, targeted therapeutic agents, and immune checkpoint inhibitors do not function well in many ccRCC patients, investigators need to develop new treatment options and further identify prognostic biomarkers and therapeutic targets ccRCC. LncRNA screening and model building based on gene instability in ccRCC may represent an important research strategy.

\section{Materials and methods Data collection}

We downloaded clinical information, protein-coding RNA expression data, lncRNA expression data, and somatic mutation information for clear renal cell carcinomas from The Cancer Genome Atlas (TCGA) database (https://portal.gdc.cancer.gov/) [18]. We considered 507 ccRCC samples with paired lncRNA and mRNA expression profiles, survival information, and clinical information.

We divided all ccRCC samples into a training set and a test set. The training set included 254 samples for the creation of a clinical outcome lncRNA risk model. The test set included 253 patients, used to validate the predictive ability of the prognostic risk model. We provided detailed data on TCGA clear cell renal carcinoma (Supplementary Table 1). Meanwhile, we calculated the tumor mutation burden (TMB) in the samples and estimate the average number of mutations in the tumor genome [19].

\section{Mining IncRNAs related to genetic instability}

First, we calculated the number of somatic mutations in each sample. The samples with the number of somatic mutations in the top 25\% were defined as the genomic unstable (GU)-like group. The samples with the number of somatic mutations in the bottom $25 \%$ were defined as the genomically stable (GS)-like group. We combined the IncRNA expression matrix of TCGA-KIRC with the GU and GS groups and obtained each group's lncRNA expression matrix. We then conducted a difference analysis on these two lncRNAs matrixes; |fold change $\mid>1$ and false discovery rate adjusted $P<0.05$ were defined as genome instability-associated lncRNAs. The result of genome instability-associated lncRNAs difference analysis is displayed in Table 1. 
Table 1 IncRNAs related to genetic instability

\begin{tabular}{llll}
\hline IncRNA & logFC & pValue & fdr \\
\hline ZNF582-AS1 & -1.067 & $2.78 \mathrm{E}-10$ & $1.32 \mathrm{E}-07$ \\
LINC01558 & -1.926 & $3.72 \mathrm{E}-10$ & $1.32 \mathrm{E}-07$ \\
GAS6-DT & -1.559 & $1.40 \mathrm{E}-09$ & $3.30 \mathrm{E}-07$ \\
AL035661.1 & -6.144 & $3.65 \mathrm{E}-07$ & $5.17 \mathrm{E}-05$ \\
AC016405.3 & 1.376 & $6.21 \mathrm{E}-05$ & $2.20 \mathrm{E}-03$ \\
AC005082.1 & -2.200 & $7.72 \mathrm{E}-05$ & $2.53 \mathrm{E}-03$ \\
LINC01187 & -8.158 & $8.16 \mathrm{E}-05$ & $2.53 \mathrm{E}-03$ \\
AL031123.1 & -2.978 & $9.95 \mathrm{E}-05$ & $2.82 \mathrm{E}-03$ \\
LINC02471 & 1.040 & $1.08 \mathrm{E}-04$ & $2.94 \mathrm{E}-03$ \\
AC079466.1 & 3.017 & $1.30 \mathrm{E}-04$ & $3.18 \mathrm{E}-03$ \\
LINC01606 & -4.716 & $1.41 \mathrm{E}-04$ & $3.33 \mathrm{E}-03$ \\
LINC01230 & -7.363 & $1.74 \mathrm{E}-04$ & $3.98 \mathrm{E}-03$ \\
AC148477.4 & -4.784 & $2.06 \mathrm{E}-04$ & $4.38 \mathrm{E}-03$ \\
LINC01896 & -6.526 & $3.24 \mathrm{E}-04$ & $6.20 \mathrm{E}-03$ \\
AC144831.1 & -1.297 & $5.42 \mathrm{E}-04$ & $8.53 \mathrm{E}-03$ \\
LINC00284 & -3.520 & $1.14 \mathrm{E}-03$ & $1.32 \mathrm{E}-02$ \\
AL139351.1 & 1.105 & $1.40 \mathrm{E}-03$ & $1.52 \mathrm{E}-02$ \\
LINC01234 & 2.170 & $1.63 \mathrm{E}-03$ & $1.67 \mathrm{E}-02$ \\
LINC00460 & 1.276 & $1.75 \mathrm{E}-03$ & $1.75 \mathrm{E}-02$ \\
MIR222HG & -1.371 & $2.25 \mathrm{E}-03$ & $1.87 \mathrm{E}-02$ \\
AP000924.1 & 1.031 & $2.15 \mathrm{E}-03$ & $1.87 \mathrm{E}-02$ \\
LINC00645 & -2.101 & $2.24 \mathrm{E}-03$ & $1.87 \mathrm{E}-02$ \\
OSTM1-AS1 & 1.425 & $3.90 \mathrm{E}-03$ & $2.71 \mathrm{E}-02$ \\
AC130371.2 & -1.271 & $4.05 \mathrm{E}-03$ & $2.73 \mathrm{E}-02$ \\
INSYN1-AS1 & -5.803 & $6.46 \mathrm{E}-03$ & $3.94 \mathrm{E}-02$ \\
AC087636.1 & 1.708 & $8.52 \mathrm{E}-03$ & $4.93 \mathrm{E}-02$ \\
\hline ICRNA L & & \\
\hline
\end{tabular}

IncRNA Long non-coding RNAs; logFC $\log _{2}$ Fold Change; fdr False discovery rate

\section{Functional enrichment analysis and GSVA}

We calculated the correlations between each proteincoding gene and the lncRNAs obtained as described above using the Pearson correlation coefficient method [20]. We ranked these protein coding factors in descending order according to the correlation and selected mRNAs with the top 10 correlation coefficients as the co-expression coding genes of lncRNA. Using functional analysis of these co-expressed coding genes, we analyzed the biological functions of these genetically unstable lncRNAs. Gene Ontology (GO) enrichment was performed using the clusterProfiler package in $\mathrm{R}$, version 3.6.3 [21]. GSVA, which is estimated in an unsupervised manner, has a higher ability to detect changes in pathways in the sample population [22]. We downloaded the GSVA score from the molecular signatures database (http://software.broadinstitute.org/gsea/msigdb) to construct the gene set. Then, GSVA score was performed for each gene set in each sample using GSVA R software package.

\section{Statistical analysis}

We used Euclidean distances and Ward's linkage method to perform hierarchical cluster analyses [23]. We used univariate Cox proportional hazard regression analysis to calculate the associations between expression level of genome instability-associated lncRNAs and overall survival. We performed multivariate Cox proportional hazard regression analysis to evaluate the weighting coefficient in the risk signature. The genome instabilityrelated lncRNA (GILncSig) for overall survival was as follows: $\log [\mathrm{h}(\mathrm{ti}) / \mathrm{h} 0(\mathrm{ti})]=\mathrm{a} 1 \mathrm{X} 1+\mathrm{a} 2 \mathrm{X} 2+\mathrm{a} 3 \mathrm{X} 3+\cdots \mathrm{akXk}$, where $\mathrm{h}(\mathrm{ti})$ is the function hazard, and $\mathrm{h} 0(\mathrm{ti})$ is the baseline hazard, X1, X2, X3, ‥Xk are covariates, and a1, a2, and $\mathrm{a} 3$ are the corresponding multivariate Cox proportional hazard regression coefficients. A detailed introduction can be found in our previous articles [24]. We were using the same best cut-off point (the point is determined by the samples, with the maximum sensitivity and specificity in time-dependent receiver operating characteristic (ROC) curve). Hazard ratio (HR) and 95\% confidence interval (CI) were calculated using Cox analysis. The Kyoto Encyclopedia of Genes and Genomes (KEGG) [25] pathway of genome instability-related lncRNAs were identified using gene set variation analysis [22]. All statistical analyses were performed using Rversion 3.6.3.

\section{Results}

\section{Differences in long non-coding RNAs}

The design flow chart of this study was shown in Fig. 1.

To identify non-coding genes related to genome instability, we grouped them according to the number of somatic mutations. We placed the first $25 \%$ of somatic mutations (84 samples) into the genetically unstable group and then placed the final $25 \%$ of somatic mutations (84 samples) into the genetically stable group. We screened and obtained differential non-coding RNAs using the limma package. We screened a total of 26 non-coding differential RNAs, of which 17 were downregulated, and nine were up-regulated (Table 1). The levels of differential non-coding RNA expression in both groups are shown in Fig. 2a.

\section{Genome instability-related IncRNA}

We performed unsupervised clustering of all samples in KIRC based on the expression levels of these 26 lncRNAs (Fig. 2b). We obtained two clustering results, and the number of somatic mutations in the two groups was significantly different (Fig. 2c, $\mathrm{P}=5.3 \mathrm{e}-13$, MannWhitney U-test). Next, we compared the expression levels of the genomic instability driver ubiquilin4 (UBQLN4) in the GS-like and the GU-like groups (Fig. 2d) [26]. We found that the expression of UBQLN4 was significantly up-regulated in the genetically unstable 


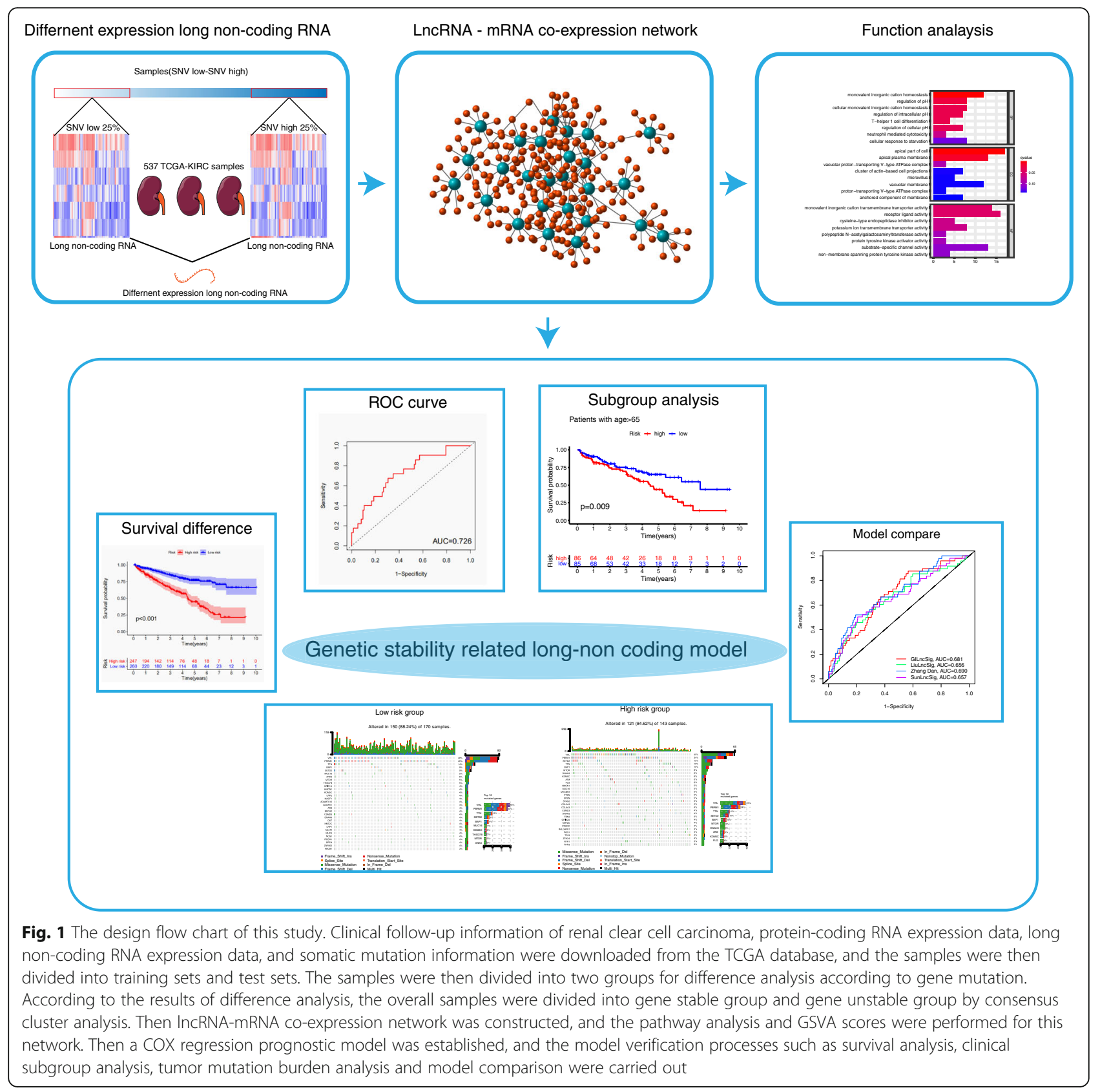

group. We supplemented the correlation coefficient between UBQLN4 and other IncRNAs (Supplementary Table 2). Based on these results, we tested whether samples with different mutation levels could be distinguished based on expression levels of the 26 differential IncRNAs, and indirectly demonstrate that these lncRNAs may be related to genome stability.

\section{LncRNA-mRNA co-expression network}

Based on Pearson correlation coefficients, we determined the top 10 mRNAs that correlated with each lncRNA. We created a co-expression network lncRNAs and mRNAs (Fig. 3a). We then analyzed the function of the mRNAs in the co-expression module to determine the associated biological processes. GO enrichment demonstrated that these protein-coding genes are related to biological processes such as homologous recombination (Fig. 3b). This analysis suggests that the 26 genomically unstable non-coding RNAs may affect genome stability by regulating their co-expression networks. We found that these co-expressed protein-coding genes might regulate homologous recombination, thereby destroying cell stability. In total, we identified 26 noncoding RNAs related to genome instability. 
A

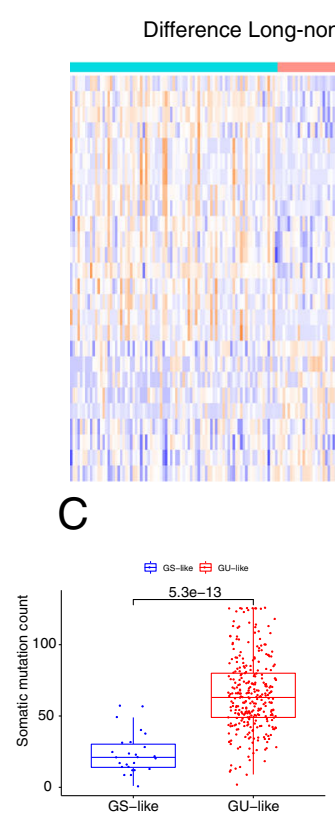

B

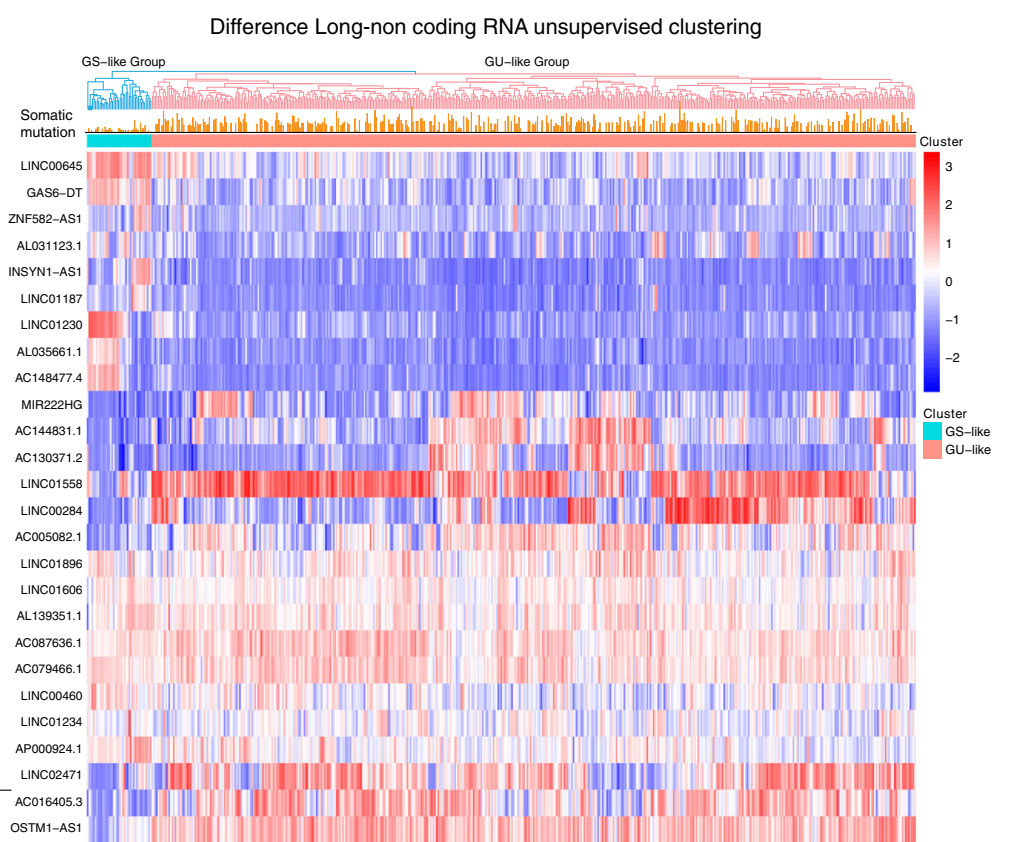

Fig. 2 (A) Difference analysis of the group that Somatic cell mutations are in the top $25 \%$ between the group that Somatic cell mutations are in the last 25\% in RCC. (B) Unsupervised clustering of GS-group and GU-group. (C) The difference of somatic cell mutation number between GSgroup and GU-Group. (D) The different expression of UBQLN4 in GS-Group and GU-Group

The genome instability-related IncRNA risk model

We clarified the lncRNAs and biological processes related to genetic stability. Next, we calculated the correlations between these lncRNAs and clinical survival phenotypes. We randomly divided 507 clear cell carcinoma samples with detailed follow-up information into training groups and validation groups. We constructed a multivariate Cox proportional hazard regression model for ccRCC in the training set based on 26 genomic stable state-related lncRNAs. The coefficients of the risk factors in the model are shown in Table 2. Risk model $($ GILncSig $)=0.095 *$ LINC00460 + $0.165 *$ LINC01234 + $0.152 *$ AL139351.1 + 0.177* MIR222HG + $0.123 *$ AC087636.1-0.027* LINC02471. We found that LINC00460, LINC01234, AL139351.1, MIR222HG, AC087636.1 were transparent risk factors. The higher their expression, the worse the overall survival of patients with renal cancer. LINC02471 is a protective factor for ccRCC. The higher its expression, the better the overall survival. We supplemented the univariate cox regression analysis coefficients of clinical features and risk scores, risk scores acted as independent prognosis factors(Supplementary Table 3). Meanwhile, we added the pearson-correlation coefficients of LINC01234 and tumor mutation burden in other types of cancers(Supplementary Figure 1). LncRNA expression patterns and the distribution of somatic mutation count distribution and UBQLN4 expression for patients in high- and lowrisk groups are shown in Supplementary Figure 2.

\section{The verification and evaluation of IncRNA model performance}

Risk scores for each sample in the training and test sets were calculated using the GILncSig method. Patients were divided into groups according to the median risk score (0.853); patients in the higher risk group had a risk score $>0.853$. We then calculated the survival difference between the high- and low-risk groups using survival analysis. In TCGA-KIRC cohort, we found that patients in the low-risk group had better clinical outcomes (Fig. 4a, P <0.001). Patients in the low-risk group in the training set (Fig. $4 \mathrm{~b}, \mathrm{P}<$ 0.001 ) and validation set (Fig. $4 c, P<0.001$ ) also had better survival outcomes. The area under the timedependent ROC curve of TCGA-KIRC cohort was 0.681 (Fig. 4d). The area under the time-dependent ROC curve of the training set cohort was 0.726 (Fig. $4 \mathrm{e})$. The area under the time-dependent ROC curve of the verification set cohort was 0.642 (Fig. 4f). MutS homolog 2 (MSH2) and replication factor $\mathrm{C}$ subunit 1 (RFC1) are involved in the process of mismatch recognition [27]. Comparison analysis showed significant 


\section{- IncRNA • mRNA}

\section{A}

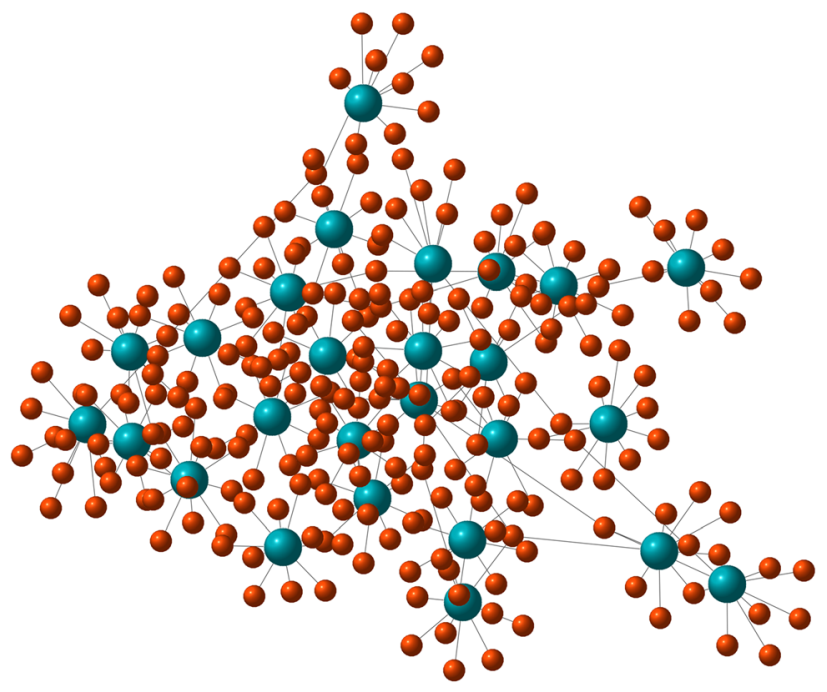

B

Homologous recombination regulation of $\mathrm{pH}$ cellular monovalent inorganic cation homeostasis regulation of intracellular $\mathrm{pH}$ T-helper 1 cell differentiation regulation of cellular $\mathrm{pH}$. neutrophil mediated cytotoxicity cellular response to starvation -

apical part of cell apical plasma membrane vacuolar proton-transporting $\mathrm{V}$-type ATPase complex cluster of actin-based cell projections microvillus

vacuolar membrane proton-transporting V-type ATPase complexanchored component of membrane-

monovalent inorganic cation transmembrane transporter activity receptor ligand activity cysteine-type endopeptidase inhibitor activity potassium ion transmembrane transporter activitypolypeptide $\mathrm{N}$-acetylgalactosaminyltransferase activity protein tyrosine kinase activator activitysubstrate-specific channel activity non-membrane spanning protein tyrosine kinase activity

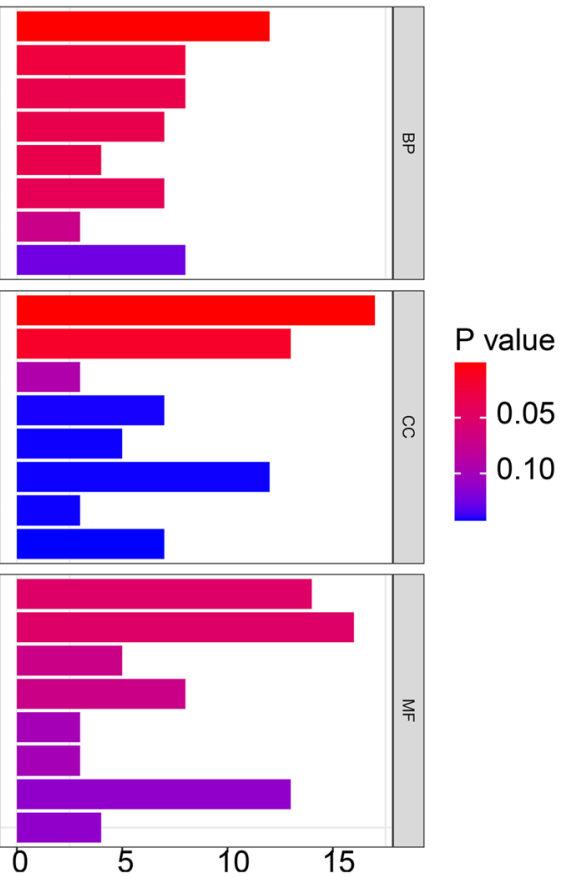

Fig. $3(\mathbf{A})$ The co-expression network of IncRNA-mRNA. Green stands for LncRNA and red for mRNA. The closer the relationship, the closer the connection. (B) Go analysis of the IncRNA-mRNA network. In the biological process, the network is mainly enriched in the monovalent inorganic homeostasis. In the cellular component, the network is mainly enriched in apical part of cell and apical plasma membrane. In the molecular function, the network is mainly enriched in monovalent inorganic cation transmembrane transporter activity and receptor ligand activity

differences in MSH2 and RFC1 expression patterns between the samples in the high- and low-risk groups (Fig. 5). Expression levels of MSH2 in the low-risk group were significantly higher than those of the high-risk group $(P<0.001$, Mann-Whitney U-test; Fig. 3d). RFC1 also showed higher expression levels in low-risk patients than in high-risk patients ( $\mathrm{P}<0.001$, Mann-Whitney U-test).

\section{Subgroups of the IncRNA model}

We then obtained a stable genomic stability-related lncRNA prognosis model. To further analyze their performance levels in various subgroups, we conducted survival analysis. We found that subgroups of patients in the low-risk group achieve better outcomes (Fig. 6)(Supplementary Figure 3). 
Table 2 Multivariate Cox proportional hazard regression analysis results

\begin{tabular}{llllll}
\hline ID & coef & HR & HR.95 L & HR.95H & $P$-value \\
\hline LINC00460 & 0.095 & 1.099 & 1.010 & 1.196 & 0.028 \\
LINC01234 & 0.165 & 1.180 & 0.984 & 1.414 & 0.044 \\
AL139351.1 & 0.152 & 1.164 & 0.966 & 1.402 & 0.010 \\
MIR222HG & 0.177 & 1.194 & 1.002 & 1.422 & 0.047 \\
AC087636.1 & 0.123 & 1.131 & 1.013 & 1.263 & 0.029 \\
LINC02471 & -0.027 & 0.973 & 0.934 & 1.014 & 0.048 \\
\hline
\end{tabular}

Coef coefficient; HR hazard rate

Tumor mutation landscapes in high- and low-risk groups

To compare mutations in the high- and low-risk groups, we drew a panorama of mutations in the two groups (Fig. 7). A total of $88.24 \%$ of the samples had mutations in the low-risk group. The top 10 mutated genes included VHL, PBRM1, TTN, SETD2, BAP1, and MUC16. The high-risk group's mutation frequency (84.62\%) was lower than that of the low-risk group (88.24\%). The top 10 factors associated with mutations were the same as those of the low-risk group.

\section{Performance comparison in terms of AUC}

To determine the accuracy of clinical predictive models related to genome stability, we performed diagnostic test comparisons. Three recently published lncRNA signatures were involved in comparisons: the three-lncRNA signature derived from Zhang et al. (Zhang Dan) [28], the four-lncRNA signature derived from Liu et al. (LiulncSig) [29] and an immune signature derived from Sun et al. (SunlncSig) [30] using the same TCGA patient cohort. As shown in Fig. 8, the AUC of overall survival for the GILncSig was 0.681, which was significantly higher than those of SunlncSig $(\mathrm{AUC}=0.657)$ and LiulncSig $(\mathrm{AUC}=0.656)$ (Fig. 8). Although our model's AUC was lower than Zhang Dan's model, our training set score was 0.726 .

\section{GSVA pathway correlation analysis}

We obtained genome stability-related lncRNA in various somatic mutation groups; however, we believe that the lncRNA obtained based on differential analysis alone is insufficient to conclude that they are related to genome stability. Therefore, in this section, we obtained genomic stability-related pathway scores of each sample using the

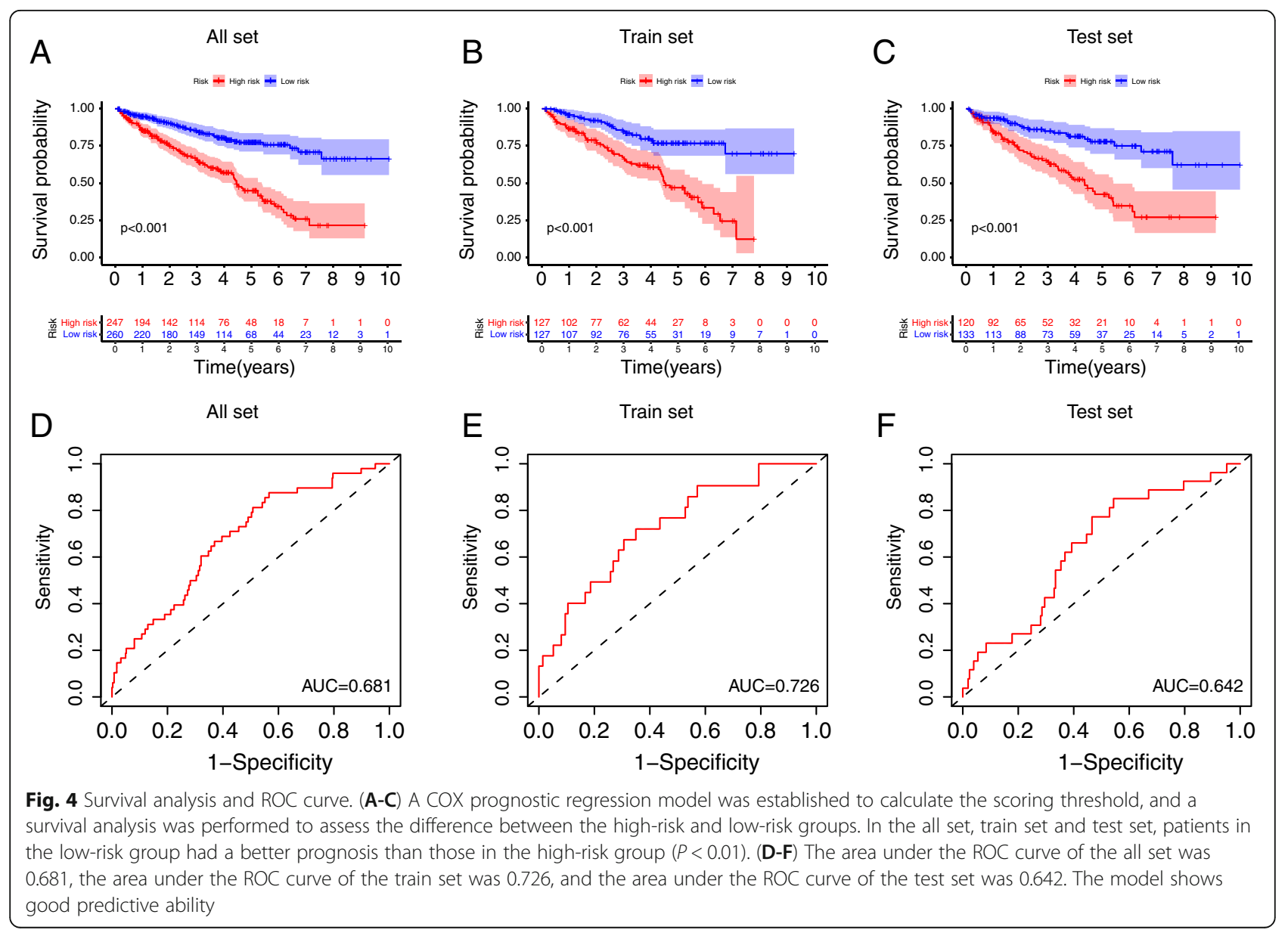



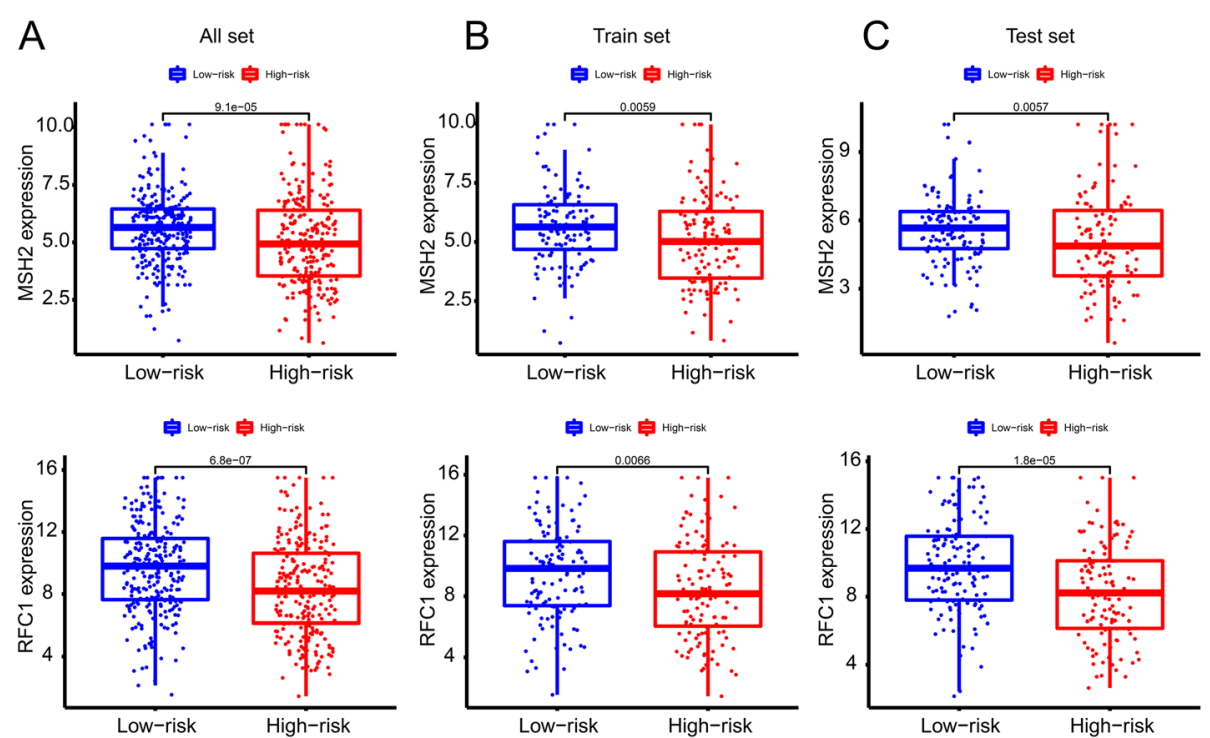

Fig. 5 (A-C) The previously reported genetic instability related factor MSH2 showed significant differences in expression patterns between highrisk group and low-risk group in the all set $(P=9.1 \mathrm{e}-05)$, train set $(P=0.0059)$ and test set $(P=0.0057)$. (D-F) The previously reported genetic instability related factor RFC1 showed significant differences in expression patterns between high-risk group and low-risk group in the all set $(P=$ 6.8e-07), train set $(P=0.0066)$ and test set $(P=1.8 \mathrm{E}-05)$

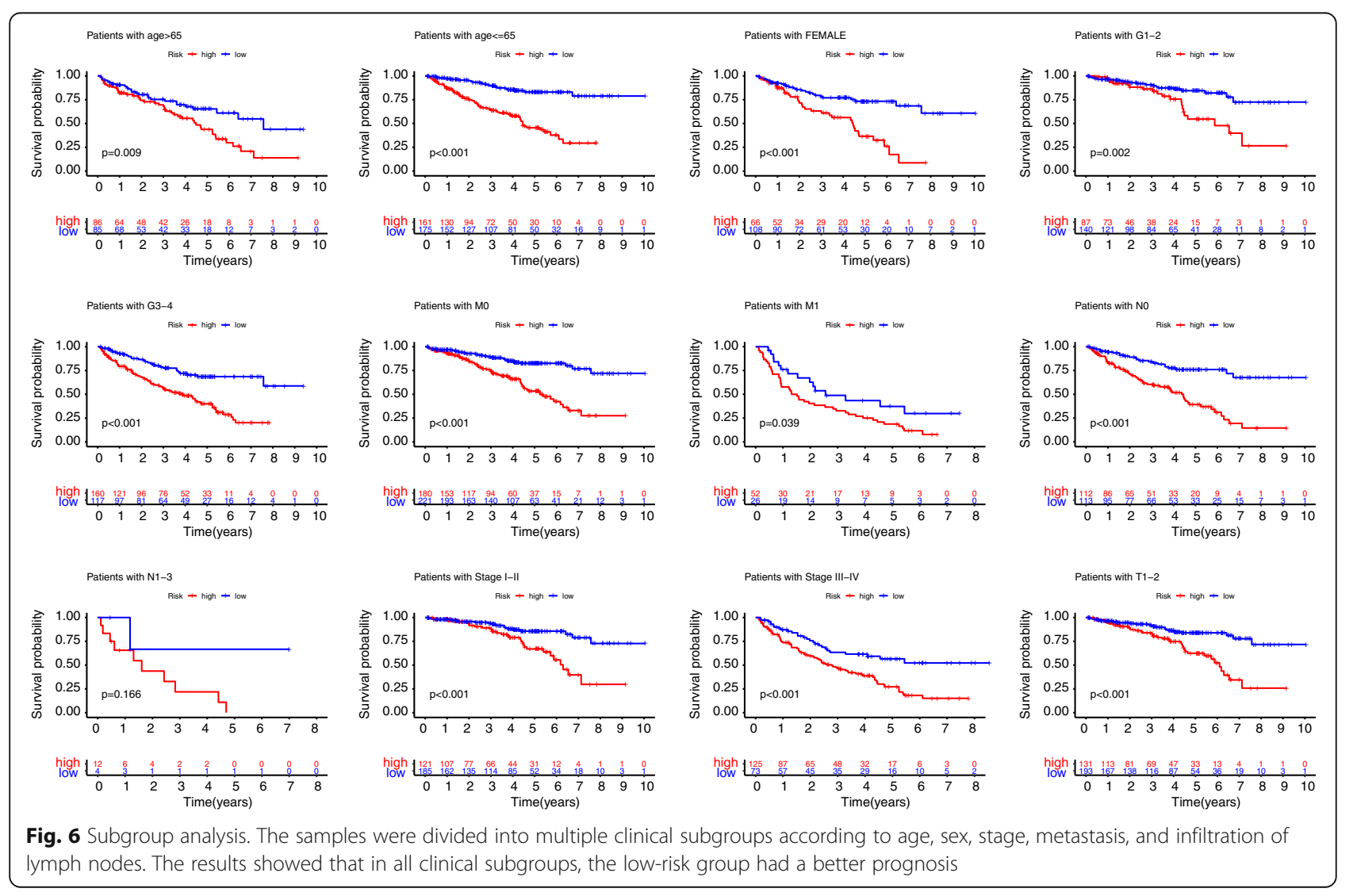



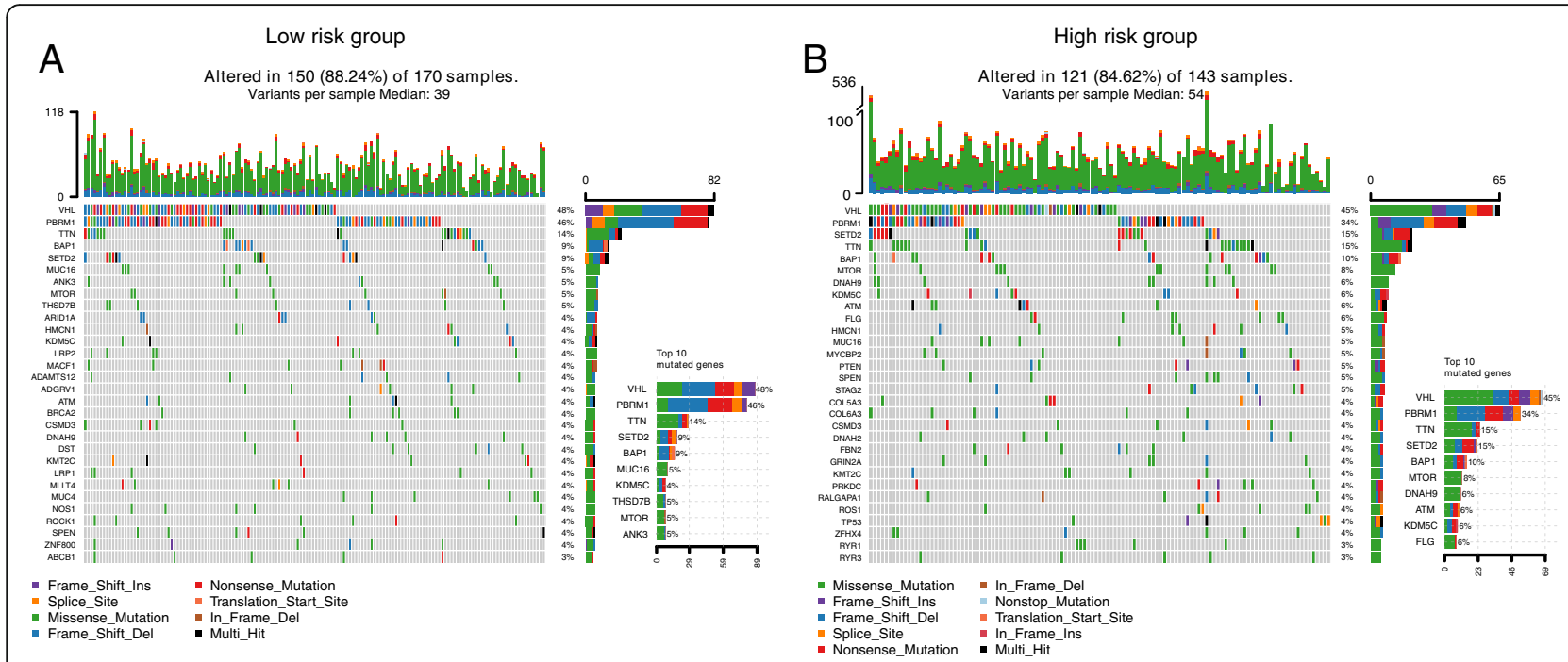

Fig. 7 Waterfall map of gene mutation burden. (A) In the low-risk group, the mutation rate was $88.24 \%$. The top three mutated genes were $V H L$, PBRM1 and TTN. (B) In the high-risk group, the mutation rate was 84.62\%. The top five mutated genes were VHL, PBRM1, SETD2, TTN and BAP1

GSVA method. We calculated the Pearson correlation coefficients of these genomic stability pathway scores and the differences in lncRNA. We directly explained the pathways in which these factors regulate genomic stability. Figure 8 shows that the base excision repair pathway, the DNA replication pathway, homologous recombination, the mismatch repair pathway, the p53 signaling pathway, and ubiquitin-mediated proteolysis were related to LINC00460 and LINC01234. The interaction of these pathways appears to ensure the stability of the genome (Fig. 9). For these reasons, we believe LINC00460 and LINC01234 affect the stability of the

\section{TCGA-ROC}

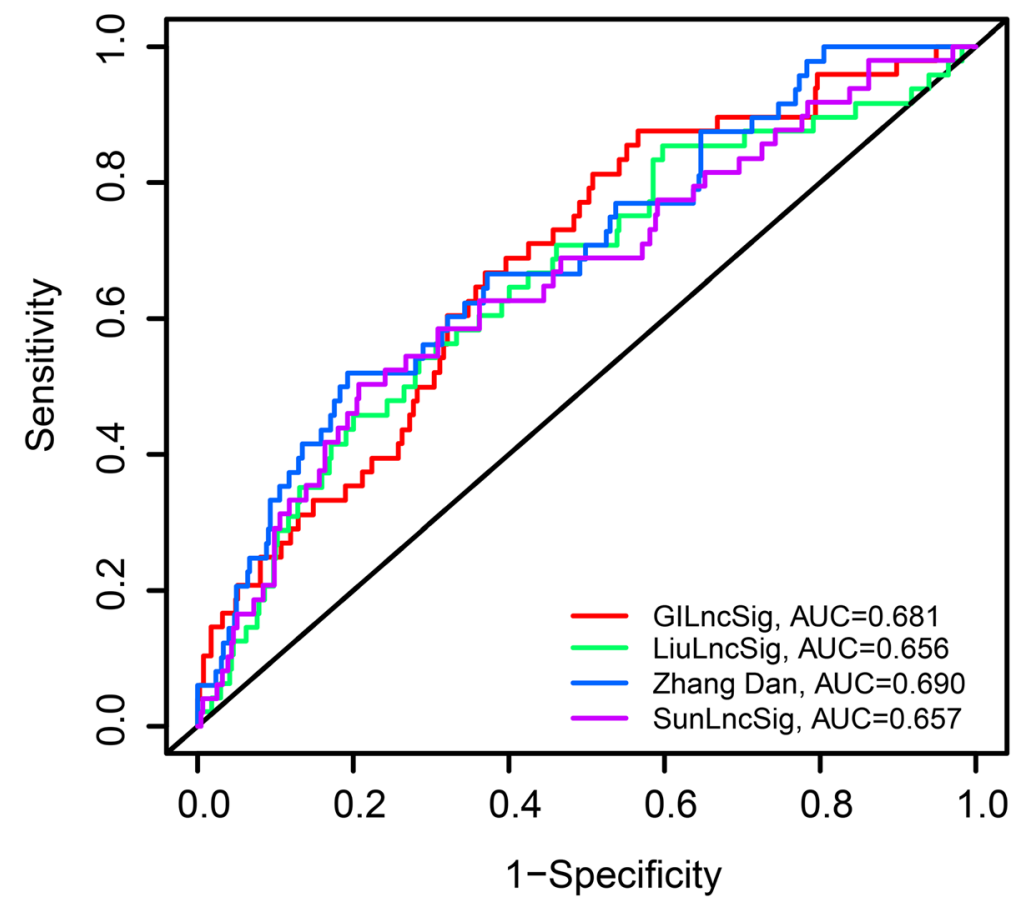

Fig. 8 Model comparison. The model proposed in this paper is compared with the model of Liu et al., Sun et al., and Zhang et al., and the model presented in this paper has the highest ROC value, indicating the best evaluation ability 

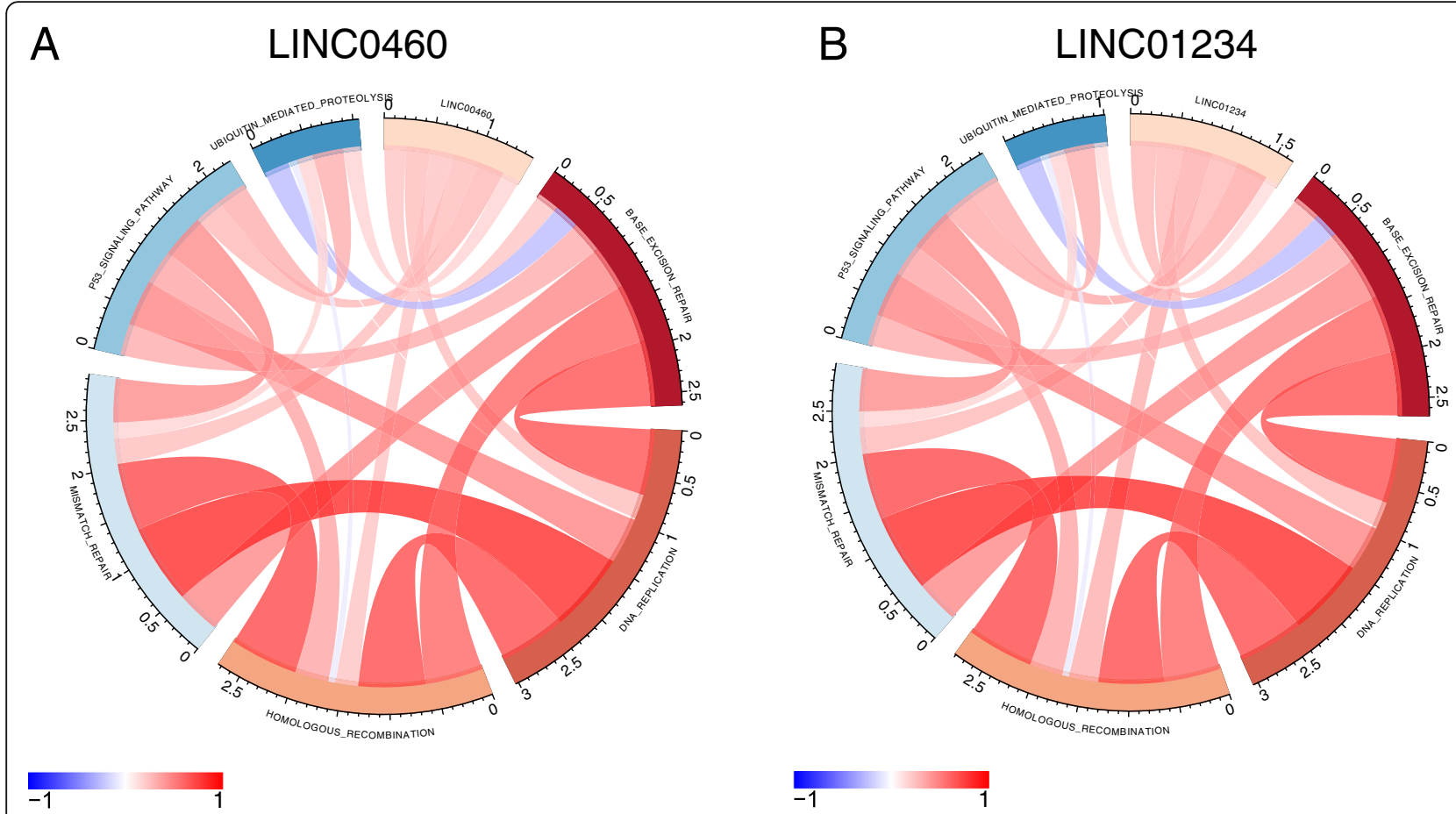

Fig. 9 Correlation analysis of IncRNA and genomic instability related pathways. Red represents positive correlation and blue represents negative correlation. The selected pathways are: P53 signaling pathway, mismatch repair, homologous recombination, DNA replication and base excision repair

genome by regulating these pathways. The correlation coefficient among genomic stability-related and lncRNAs were performed in Supplementary Table 4.

\section{Discussion}

The genome structure's relative stability is a prerequisite for the maintenance and continuation of the biological germline. It is crucial to ensure that a set of effective mechanisms is formed in the cell. There is a stable and accurate transmission of genetic information from generation to generation. Chromosome instability refers to the increased probability of acquiring chromosomal aberrations due to defects in processes such as DNA repair, replication, or chromosome segregation. Genome stability is closely related to the occurrence and progression of cancer [31-33]. Common DNA damage types include DNA base modification, DNA inter-strand, and intra-strand cross-links, and DNA single-strand and double-strand breaks [34]. Such DNA damage often leads to genome instability. Proteins related to DNA damage repair, DNA replication, and cell cycle checkpoints work together to ensure the integrity of the genome and the DNA structure's integrity. However, mutations in these proteins can lead to the accumulation of mutations in chromosomes; as these mutations accumulate, they cause cancer and premature aging [32, 33, 35]. There is no accurate quantitative way to describe genome instability. Various efforts are underway to identify protein-coding genes and microRNAs related to genomic instability that predict outcomes [36-38].

Although we have made substantial efforts to identify lncRNAs related to genomic instability, whole-genome identification of lncRNA and its clinical research are still in their early stages.

Based on TCGA clear cell cancer cohort and the corresponding number of somatic mutations, we identified 26 differences related to the number of somatic mutations at the computational level. However, the analysis in computational biology is insufficient. Therefore, we combined clinical prognostic phenotype. A clinical predictive lncRNA model was constructed. We found that six lncRNAs in the model could be used as independent prognostic markers for renal cancer. According to our understanding, genome stability is closely related to levels of p53 mutations, DNA repair, and base mismatch repair. On account of the cumulative effect of these factors, normal cells gradually become cancer cells. According to our previous description, the six lncRNAs in the model should be closely related to these processes. Therefore, to verify this point of view, we performed GSVA gene set analysis and obtained the KEGG pathway scores corresponding to each sample. Then, the Pearson correlation coefficient test was performed using these pathways. LINC00460 and LINC01234 are the 
most relevant to these genomic stability pathways. We demonstrated that this method could screen candidate genome stability-related lncRNAs and identify the relevant pathways involved in these lncRNAs through GSVA analysis.

After a careful literature search, we found that the biological process of LINC00460 and LINC01234 in the GILncSig has not been reported to date. We found that the IncRNA LINC00460 was located on chromosome $13 \mathrm{q} 33.2$ and is a prognostic biomarker for esophageal squamous cell carcinoma [39] and renal carcinoma [28]. Another lncRNA, LINC01234, is located on chromosome 12q24.13. LINC01234 was found to regulate proliferation, migration, and invasion of ccRCC cells via the HIF-2 $\alpha$ pathway [40]. Although studies have demonstrated the relationship between these two factors and outcomes of RCC, they do not explain the specifically related mechanisms. Finally, by analyzing the GSVA pathway, we found that they have the strongest correlation with the p53 pathway and affect the stability of the genome.

The transcription of lncRNA can affect the expression of neighboring genes [41]. Ephrin B2 (EFNB2), the neighboring gene of LINC00460, encoded the Ephrin family. Overexpression of EFNB2 is associated with malignant progression of tumors. It is expressed at high levels in head and neck squamous cell carcinoma and colorectal cancer [42], also promotes the growth of pancreatic ductal adenocarcinoma [43]. Knocking down EFNB2 can block tumorigenesis and establish tumor therapy [44].

RNA binding motif protein 19 (RBM19), the neighboring gene of LINC01234, Its function may be to participate in the regulation of ribosome biogenesis $[45,46]$. Although there have been no specific studies linking RBM19 to cancer, other scientists have found that RBM19 is a gene expressed in the intestinal epithelium and is critical for intestinal morphogenesis [47].

There are some limitations to our study. First, we did not conduct cell or animal experiments. Second, we only identified 26 genomic stability-related lncRNAs; nevertheless, computational biology techniques demonstrated the connection between LINC00460 and LINC01234 and the genome stability pathway. Underlying regulatory mechanisms require further exploration.

In conclusion, we constructed a screening system for genome stability-related lncRNAs, and we identified 26 genomic stability-related lncRNAs, the detailed introduction of the $26 \mathrm{lnc}$ RNAs was uploaded as Supplementary Table 5. We used these lncRNAs to predict outcomes in patients with ccRCC and found that these lncRNAs can be used as independent predictors. Finally, using GSVA pathway correlation analysis, we found that LNC00460 and LINC01234 are related to genome stability, and we indirectly demonstrated the appropriateness of this strategy.

\section{Supplementary Information}

The online version contains supplementary material available at https://doi. org/10.1186/s12885-021-08356-9.

\section{Additional file 1.}

Additional file 2. (XLS $166 \mathrm{~kb})$

Additional file 3.

Additional file 4.

Additional file 5.

Additional file 6.

Additional file 7.

Additional file 8. LncRNAs related to genetic instability [48-70].

Acknowledgements

We appreciate the free use of TCGA databases.

Authors' contributions

Yutao Wang, Kexin Yan and Jianbin Bi designed the study; Yutao Wang, Kexin Yan and Linhui Wang analyzed and wrote the manuscript. All authors read and agreed to the final version of the manuscript.

Funding

This work was supported by China Shenyang Science and Technology Plan (20-205-4-015).

Availability of data and materials

"The datasets analysed during the current study are available in the TCGA repository, [https://portal.gdc.cancer.gov/]".

\section{Declarations}

Ethics approval and consent to participate Not applicable.

Consent for publication

Not applicable.

\section{Competing interests}

The authors declare no conflict of interest.

\section{Author details}

${ }^{1}$ Department of Urology, China Medical University, The First Hospital of China Medical University, Shenyang, Liaoning, China. ${ }^{2}$ Department of Dermatology, China Medical University, The First Hospital of China Medical University, Shenyang, Liaoning, China.

Received: 7 February 2021 Accepted: 29 April 2021

Published online: 24 June 2021

References

1. Dagher J, Delahunt B, Rioux-Leclercq N, Egevad L, Srigley JR, Coughlin G, et al. Clear cell renal cell carcinoma: validation of World Health Organization/International Society of Urological Pathology grading. Histopathology. 2017;71(6):918-25. https://doi.org/10.1111/his.13311.

2. Makhov P, Joshi S, Ghatalia P, Kutikov A, Uzzo RG, Kolenko VM. Resistance to systemic therapies in clear cell renal cell carcinoma: mechanisms and management strategies. Mol Cancer Ther. 2018;17(7):1355-64. https://doi. org/10.1158/1535-7163.MCT-17-1299.

3. Mehdi A, Riazalhosseini Y. Epigenome aberrations: emerging driving factors of the clear cell renal cell carcinoma. Int J Mol Sci. 2017;18(8). https://doi. org/10.3390/ijms18081774. 
4. Woo S, Suh CH, Kim SY, Cho JY, Kim SH. Diagnostic Performance of DWI for Differentiating High- From Low-Grade Clear Cell Renal Cell Carcinoma: A Systematic Review and Meta-Analysis. AJR Am J Roentgenol. 2017;209: W374-374W381.

5. Vera-Badillo FE, Templeton AJ, Duran I, Ocana A, de Gouveia P, Aneja P, et al. Systemic therapy for non-clear cell renal cell carcinomas: a systematic review and meta-analysis. Eur Urol. 2015;67(4):740-9. https://doi.org/10.101 6/j.eururo.2014.05.010.

6. Abbas T, Keaton MA, Dutta A. Genomic instability in cancer. Cold Spring Harb Perspect Biol. 2013;5:a012914.

7. Pikor L, Thu K, Vucic E, Lam W. The detection and implication of genome instability in cancer. Cancer Metastasis Rev. 2013;32(3-4):341-52. https://doi. org/10.1007/s10555-013-9429-5.

8. Gaillard H, García-Muse T, Aguilera A. Replication stress and cancer. Nat Rev Cancer. 2015;15(5):276-89. https://doi.org/10.1038/nrc3916.

9. Reis AH, Vargas FR, Lemos B. Biomarkers of genome instability and cancer epigenetics. Tumour Biol. 2016;37(10):13029-38. https://doi.org/10.1007/s132 77-016-5278-5.

10. Djebali S, Davis CA, Merkel A, Dobin A, Lassmann T, Mortazavi A, et al. Landscape of transcription in human cells. Nature. 2012;489:101-8.

11. Renganathan A, Felley-Bosco E. Long noncoding RNAs in Cancer and therapeutic potential. Adv Exp Med Biol. 2017;1008:199-222. https://doi. org/10.1007/978-981-10-5203-3_7.

12. Thin KZ, Liu X, Feng X, Raveendran S, Tu JC. LncRNA-DANCR: a valuable cancer related long non-coding RNA for human cancers. Pathol Res Pract. 2018;214(6):801-5. https://doi.org/10.1016/j.prp.2018.04.003.

13. Ransohoff JD, Wei Y, Khavari PA. The functions and unique features of long intergenic non-coding RNA. Nat Rev Mol Cell Biol. 2018;19(3):143-57. https://doi.org/10.1038/nrm.2017.104.

14. Lam MT, Li W, Rosenfeld MG, Glass CK. Enhancer RNAs and regulated transcriptional programs. Trends Biochem Sci. 2014;39(4):170-82. https://doi. org/10.1016/j.tibs.2014.02.007.

15. Li W, Notani D, Ma Q, Tanasa B, Nunez E, Chen AY, et al. Functional roles of enhancer RNAs for oestrogen-dependent transcriptional activation. Nature. 2013;498(7455):516-20. https://doi.org/10.1038/nature12210.

16. Fang Y, Fullwood MJ. Roles, functions, and mechanisms of long non-coding RNAs in Cancer. Genomics Proteomics Bioinformatics. 2016;14(1):42-54. https://doi.org/10.1016/j.gpb.2015.09.006.

17. Bhan A, Soleimani M, Mandal SS. Long noncoding RNA and Cancer: a new paradigm. Cancer Res. 2017;77(15):3965-81. https://doi.org/10.1158/0008-54 72.CAN-16-2634

18. Wang Z, Jensen MA, Zenklusen JC. A practical guide to the Cancer genome atlas (TCGA). Methods Mol Biol. 2016;1418:111-41. https://doi.org/10.1007/ 978-1-4939-3578-9_6.

19. Schumacher TN, Kesmir C, van Buuren MM. Biomarkers in cancer immunotherapy. Cancer Cell. 2015;27(1):12-4. https://doi.org/10.1016/j. ccell.2014.12.004.

20. Pripp AH. Pearson's or Spearman's correlation coefficients. Tidsskr Nor Laegeforen. 2018;138(8). https://doi.org/10.4045/tidsskr.18.0042.

21. Ashburner M, Ball CA, Blake JA, Botstein D, Butler H, Cherry JM, et al. Gene ontology: tool for the unification of biology. Gene Ontol Consortium Nat Genet. 2000;25(1):25-9. https://doi.org/10.1038/75556.

22. Hänzelmann S, Castelo R, Guinney J. GSVA: gene set variation analysis for microarray and RNA-seq data. BMC Bioinformatics. 2013;14:7.

23. Vogt W, Nagel D. Cluster analysis in diagnosis. Clin Chem. 1992;38(2):182-98. https://doi.org/10.1093/clinchem/38.2.182.

24. Wang $Y$, Lin J, Yan K, Wang J. Identification of a robust five-gene risk model in prostate Cancer: a robust likelihood-based survival analysis. Int $J$ Genomics. 2020;2020:1097602.

25. Kanehisa M, Furumichi M, Tanabe M, Sato Y, Morishima K. KEGG: new perspectives on genomes, pathways, diseases and drugs. Nucleic Acids Res. 2017;45:D353-353D361.

26. Jachimowicz RD, Beleggia F, Isensee J, Velpula BB, Goergens J, Bustos MA, et al. UBQLN4 Represses Homologous Recombination and Is Overexpressed in Aggressive Tumors. Cell. 2019;176:505-19.e22.

27. Surtees JA, Alani E. Replication factors license exonuclease I in mismatch repair. Mol Cell. 2004;15(2):164-6. https://doi.org/10.1016/j. molcel.2004.07.004.

28. Zhang D, Zeng S, Hu X. Identification of a three-long noncoding RNA prognostic model involved competitive endogenous RNA in kidney renal clear cell carcinoma. Cancer Cell Int. 2020;20(1):319. https://doi.org/10.1186/ s12935-020-01423-4.

29. Liu Y, Gou X, Wei Z, Yu H, Zhou X, Li X. Bioinformatics profiling integrating a four immune-related long non-coding RNAs signature as a prognostic model for papillary renal cell carcinoma. Aging (Albany NY). 2020;12:15359-73.

30. Sun Z, Jing C, Xiao C, Li T. Long non-coding RNA profile study identifies an immune-related IncRNA prognostic signature for kidney renal clear cell carcinoma. Front Oncol. 2020;10:1430. https://doi.org/10.3389/fonc.2020. 01430.

31. Aguilera A, García-Muse T. Causes of genome instability. Annu Rev Genet. 2013;47(1):1-32. https://doi.org/10.1146/annurev-genet-111212-133232.

32. Cha HJ, Yim H. The accumulation of DNA repair defects is the molecular origin of carcinogenesis. Tumour Biol. 2013;34(6):3293-302. https://doi.org/1 0.1007/s13277-013-1038-y.

33. Basu AK. DNA damage, mutagenesis and Cancer. Int J Mol Sci. 2018;19(4). https://doi.org/10.3390/ijms19040970.

34. Kramara J, Osia B, Malkova A. Break-induced replication: the where, the why, and the how. Trends Genet. 2018;34(7):518-31. https://doi.org/10.1016/j.tig.2 018.04.002.

35. Cotterill S. Diseases associated with mutation of replication and repair proteins. Adv Exp Med Biol. 2018;1076:215-34. https://doi.org/10.1007/978981-13-0529-0_12

36. Habermann JK, Doering J, Hautaniemi S, Roblick UJ, Bündgen NK, Nicorici D, et al. The gene expression signature of genomic instability in breast cancer is an independent predictor of clinical outcome. Int J Cancer. 2009;124(7): 1552-64. https://doi.org/10.1002/ijc.24017.

37. Mettu RK, Wan YW, Habermann JK, Ried T, Guo NL. A 12-gene genomic instability signature predicts clinical outcomes in multiple cancer types. Int Biol Markers. 2010;25(4):219-28. https://doi.org/10.5301/JBM.2010.6079.

38. Ferguson LR, Chen $\mathrm{H}$, Collins AR, Connell M, Damia G, Dasgupta S, et al. Genomic instability in human cancer: Molecular insights and opportunities for therapeutic attack and prevention through diet and nutrition. Semin Cancer Biol. 2015;35:Suppl:S5-5S24.

39. Liang $Y$, Wu $Y$, Chen $X$, Zhang $S$, Wang $K$, Guan $X$, et al. A novel long noncoding RNA linc00460 up-regulated by CBP/P300 promotes carcinogenesis in esophageal squamous cell carcinoma. Biosci Rep. 2017; 37(5). https://doi.org/10.1042/BSR20171019.

40. Yang F, Liu C, Zhao G, Ge L, Song Y, Chen Z, et al. Long non-coding RNA LINC01234 regulates proliferation, migration and invasion via HIF-2a pathways in clear cell renal cell carcinoma cells. PeerJ. 2020:8:e10149. https://doi.org/10.7717/peerj.10149.

41. Engreitz JM, Haines JE, Perez EM, Munson G, Chen J, Kane M, et al. Local regulation of gene expression by IncRNA promoters, transcription and splicing. Nature. 2016;539(7629):452-5. https://doi.org/10.1038/nature20149.

42. Scherer D, Deutelmoser H, Balavarca Y, Toth R, Habermann N, Buck K, et al. Polymorphisms in the angiogenesis-related genes EFNB2, MMP2 and JAG1 are associated with survival of colorectal Cancer patients. Int J Mol Sci. 2020; 21(15). https://doi.org/10.3390/ijms21155395.

43. Zhu F, Dai SN, Xu DL, Hou CQ, Liu TT, Chen QY, et al. EFNB2 facilitates cell proliferation, migration, and invasion in pancreatic ductal adenocarcinoma via the p53/p21 pathway and EMT. Biomed Pharmacother. 2020;125:109972. https://doi.org/10.1016/j.biopha.2020.109972.

44. Krusche B, Ottone C, Clements MP, Johnstone ER, Goetsch K, Lieven H, et al. EphrinB2 drives perivascular invasion and proliferation of glioblastoma stem-like cells. Elife. 2016:5. https://doi.org/10.7554/eLife.14845.

45. Kallberg Y, Segerstolpe Å, Lackmann F, Persson B, Wieslander L. Evolutionary conservation of the ribosomal biogenesis factor Rbm19/Mrd1: implications for function. PLoS One. 2012;7(9):e43786. https://doi.org/10.1371/journal.pone.0043786.

46. Zhang J, Tomasini AJ, Mayer AN. RBM19 is essential for preimplantation development in the mouse. BMC Dev Biol. 2008;8(1):115. https://doi.org/1 0.1186/1471-213X-8-115.

47. Lorenzen JA, Bonacci BB, Palmer RE, Wells C, Zhang J, Haber DA, et al. $\mathrm{Rbm} 19$ is a nucleolar protein expressed in crypt/progenitor cells of the intestinal epithelium. Gene Expr Patterns. 2005;6(1):45-56. https://doi.org/1 0.1016/j.modgep.2005.05.001

48. Yang W, Zhang K, Li L, Xu Y, Ma K, Xie H, et al. Downregulation of IncRNA ZNF582-AS1 due to DNA hypermethylation promotes clear cell renal cell carcinoma growth and metastasis by regulating the N(6)-methyladenosine modification of MT-RNR1. J Exp Clin Cancer Res. 2021;40(1):92. https://doi. org/10.1186/s13046-021-01889-8. 
49. Kumegawa K, Maruyama R, Yamamoto E, Ashida M, Kitajima H, Tsuyada A, et al. A genomic screen for long noncoding RNA genes epigenetically silenced by aberrant DNA methylation in colorectal cancer. Sci Rep. 2016; 6(1):26699. https://doi.org/10.1038/srep26699.

50. Li Z, Jiang M, Zhang T, Liu S. GAS6-AS2 Promotes Hepatocellular Carcinoma via miR-3619-5p/ARL2 Axis Under Insufficient Radiofrequency Ablation Condition. Cancer Biother Radiopharm. 2020. https://doi.org/10.1089/cbr.201 9.3541.

51. Ren S, Xu Y. AC016405.3, a novel long noncoding RNA, acts as a tumor suppressor through modulation of TET2 by microRNA-19a-5p sponging in glioblastoma. Cancer Sci. 2019;110(5):1621-32. https://doi.org/10.1111/ cas. 14002.

52. Skala SL, Wang X, Zhang Y, Mannan R, Wang L, Narayanan SP, et al. Nextgeneration RNA sequencing-based biomarker characterization of Chromophobe renal cell carcinoma and related Oncocytic neoplasms. Eur Urol. 2020;78(1):63-74. https://doi.org/10.1016/j.eururo.2020.03.003.

53. Chen D, Huang Z, Ning Y, Lou C. Knockdown of LINC02471 inhibits papillary thyroid carcinoma cell invasion and metastasis by targeting miR-375. Cancer Manag Res. 2020;12:8757-71. https://doi.org/10.2147/CMAR.S243767.

54. Li W, Chen QF, Huang T, Wu P, Shen L, Huang ZL. Identification and validation of a prognostic IncRNA signature for hepatocellular carcinoma. Front Oncol. 2020;10:780. https://doi.org/10.3389/fonc.2020.00780.

55. Luo Y, Tan W, Jia W, Liu Z, Ye P, Fu Z, et al. The long non-coding RNA LINC01606 contributes to the metastasis and invasion of human gastric cancer and is associated with Wnt/ß-catenin signaling. Int J Biochem Cell Biol. 2018;103:125-34. https://doi.org/10.1016/j.biocel.2018.08.012.

56. Liu L, Wang Z, Jia J, Shi Y, Lian T, Han X. Linc01230, transcriptionally regulated by PPARY, is identified as a novel modifier in endothelial function. Biochem Biophys Res Commun. 2018;507(1-4):369-76. https://doi.org/10.101 6/j.bbrc.2018.11.045.

57. Chen Y, Mao ZD, Shi YJ, Qian Y, Liu ZG, Yin XW, et al. Comprehensive analysis of miRNA-mRNA-IncRNA networks in severe asthma. Epigenomics. 2019;11(2):115-31. https://doi.org/10.2217/epi-2018-0132.

58. Wang S, Zhang L, Tao L, Pang L, Fu R, Fu Y, et al. Construction and investigation of an LINC00284-associated regulatory network in serous ovarian carcinoma. Dis Markers. 2020;2020:9696285.

59. Vidovic D, Huynh TT, Konda P, Dean C, Cruickshank BM, Sultan M, et al. ALDH1A3-regulated long non-coding RNA NRAD1 is a potential novel target for triple-negative breast tumors and cancer stem cells. Cell Death Differ. 2020;27(1):363-78. https://doi.org/10.1038/s41418-019-0362-1.

60. Xing C, Cai Z, Gong J, Zhou J, Xu J, Guo F. Identification of potentia biomarkers involved in gastric Cancer through integrated analysis of noncoding RNA associated competing endogenous RNAs network. Clin Lab. 2018;64(10):1661-9. https://doi.org/10.7754/Clin.Lab.2018.180419.

61. Zhao Y, Wang H, Wu C, Yan M, Wu H, Wang J, et al. Construction and investigation of IncRNA-associated ceRNA regulatory network in papillary thyroid cancer. Oncol Rep. 2018;39(3):1197-206. https://doi.org/10.3892/or.2 018.6207.

62. Chen Z, Chen X, Lei T, Gu Y, Gu J, Huang J, et al. Integrative analysis of NSCLC identifies LINC01234 as an oncogenic IncRNA that interacts with HNRNPA2B1 and regulates miR-106b biogenesis. Mol Ther. 2020;28(6):147993. https://doi.org/10.1016/j.ymthe.2020.03.010.

63. Liu D, Jian X, Xu P, Zhu R, Wang Y. Linc01234 promotes cell proliferation and metastasis in oral squamous cell carcinoma via miR-433/PAK4 axis. BMC Cancer. 2020;20(1):107. https://doi.org/10.1186/s12885-020-6541-0.

64. Ma J, Han LN, Song JR, Bai XM, Wang JZ, Meng LF, et al. Long noncoding RNA LINC01234 silencing exerts an anti-oncogenic effect in esophageal cancer cells through microRNA-193a-5p-mediated CCNE1 downregulation. Cell Oncol (Dordr). 2020;43:377-94.

65. Zhu Y, Luo C, Korakkandan AA, Fatma Y, Tao Y, Yi T, et al. Function and regulation annotation of up-regulated long non-coding RNA LINC01234 in gastric cancer. J Clin Lab Anal. 2020;34:e23210.

66. Xu W, Li K, Song C, Wang X, Li Y, Xu B, et al. Knockdown of IncRNA LINC01234 suppresses the tumorigenesis of liver Cancer via sponging miR-513a-5p. Front Oncol. 2020;10:571565. https://doi.org/10.3389/fonc.2020.571565.

67. Chaudhary R, Wang X, Cao B, De La Iglesia J, Masannat J, Song F, et al. Long noncoding RNA, LINC00460, as a prognostic biomarker in head and neck squamous cell carcinoma (HNSCC). Am J Transl Res. 2020;12(2):684-96.

68. Li X, Sun L, Wang X, Wang N, Xu K, Jiang X, et al. A five immune-related IncRNA signature as a prognostic target for Glioblastoma. Front Mol Biosci. 2021;8:632837. https://doi.org/10.3389/fmolb.2021.632837.
69. Fan CN, Ma L, Liu N. Comprehensive analysis of novel three-long noncoding RNA signatures as a diagnostic and prognostic biomarkers of human triple-negative breast cancer. J Cell Biochem. 2019;120(3):3185-96. https://doi.org/10.1002/jcb.27584.

70. Li C, Zheng H, Hou W, Bao H, Xiong J, Che W, et al. Long non-coding RNA linc00645 promotes TGF- $\beta$-induced epithelial-mesenchymal transition by regulating miR-205-3p-ZEB1 axis in glioma. Cell Death Dis. 2019;10(10):717. https://doi.org/10.1038/s41419-019-1948-8.

\section{Publisher's Note}

Springer Nature remains neutral with regard to jurisdictional claims in published maps and institutional affiliations.
Ready to submit your research? Choose BMC and benefit from:

- fast, convenient online submission

- thorough peer review by experienced researchers in your field

- rapid publication on acceptance

- support for research data, including large and complex data types

- gold Open Access which fosters wider collaboration and increased citations

- maximum visibility for your research: over $100 \mathrm{M}$ website views per year

At BMC, research is always in progress.

Learn more biomedcentral.com/submissions 